\title{
Subtotal surgical therapy for localized prostate cancer: a single-center precision prostatectomy experience in 25 patients, and SEER-registry data analysis
}

\author{
Akshay Sood $^{1,2}$, Wooju Jeong ${ }^{1}$, Jacob Keeley $^{2}$, Firas Abdollah $^{1,2}$, Oudai Hassan $^{3}$, Nilesh Gupta $^{3}$, \\ Mani Menon ${ }^{1,2}$ \\ ${ }^{1}$ Vattikuti Urology Institute, Henry Ford Hospital, Detroit, MI, USA; ${ }^{2}$ VCORE - Vattikuti Urology Institute Center for Outcomes Research, \\ Analytics and Evaluation, Henry Ford Hospital, Detroit, MI, USA; ${ }^{3}$ Department of Pathology, Henry Ford Hospital, Detroit, MI, USA \\ Contributions: (I) Conception and design: A Sood, M Menon; (II) Administrative support: M Menon; (III) Provision of study materials or patients: \\ A Sood, W Jeong, F Abdollah, O Hassan, N Gupta, M Menon; (IV) Collection and assembly of data: A Sood, J Keeley; (V) Data analysis and \\ interpretation: A Sood, J Keeley; (VI) Manuscript writing: All authors; (VII) Final approval of manuscript: All authors. \\ Correspondence to: Akshay Sood, MD. Vattikuti Urology Institute, Henry Ford Hospital, 2799 W. Grand Boulevard, Detroit 48202, MI, USA. \\ Email: asood1@hfhs.org.
}

Background: We recently described a novel form of focal therapy for prostate cancer $(\mathrm{CaP})$ - the precision prostatectomy. Here we report on the first 25 consecutive patients. Further, utilizing Surveillance Epidemiology and End Results (SEER)-registry data, we assess long-term oncological efficacies of various focal therapy techniques.

Methods: Men who met the criteria: (I) PSA $\leq 15 \mathrm{ng} / \mathrm{mL}$, (II) stage $\leq \mathrm{cT} 2$, (III) dominant unilateral lesion with Gleason $\leq 4+3$ with any number or percentage (\%) of cores involved ipsilaterally on biopsy, (IV) no primary Gleason $\geq 4$ contralaterally, and (V) preoperative erectile function score (IIEF-5/SHIM) of $\geq 17$ with/without PDE-5i were included in this prospective, single-arm, IDEAL stage 2b study (December 2016 to July 2017). Safety of the technique, and intermediate-term urinary, sexual and oncological outcomes were studied. Descriptive statistics and Kaplan-Meier (KM) analysis were used to assess 12-month urinary continence (0-1 pad), 12 -month sexual potency (SHIM $\geq 17$ ), and 36-month freedom from clinicallysignificant $\mathrm{CaP}$ (grade group $\geq 2$ ), radical treatment, metastatic disease and mortality. SEER-registry was queried to evaluate $\mathrm{CaP}$-specific survival in patients undergoing hyperthermia, cryotherapy, or segmental prostatectomy.

Results: At study entry, the median (IQR) age, PSA and SHIM score were 56.5 (53.1-62.3) years, 4.2 (3.8-5.9) ng/mL and 23 [20-25], respectively. Only 1 patient met the Epstein criteria for active surveillance. All patients were followed for a minimum of 2 years. At 12 months, from a functional standpoint, all patients were continent. Twenty-three (92\%) patients were potent at 12 months. From an oncological standpoint, at 36 months, the KM analysis (95\% CI) demonstrated a 96.2\% (92.9-98.7) rate of freedom from clinicallysignificant $\mathrm{CaP}$ and a 92.7\% (88.9-97.2) rate of freedom from radical treatment. All patients were alive and free of metastatic disease at the latest follow-up. Analysis of the SEER-registry data demonstrated 10-year CaP-specific survival rates of $91.6 \%$ to $97.7 \%$ among the 3 studied modalities, $\mathrm{P}=0.298$.

Conclusions: Precision prostatectomy is feasible, technically safe, and offers excellent postoperative functional results. At 36 months of follow-up, the oncological outcomes and secondary procedure rates appear to be at-par with the ablative forms of focal therapy.

Keywords: Focal therapy; robotics; prostate cancer $(\mathrm{CaP})$; prostatectomy

Submitted Dec 04, 2020. Accepted for publication May 18, 2021.

doi: $10.21037 /$ tau-20-1476

View this article at: http://dx.doi.org/10.21037/tau-20-1476 


\section{Introduction}

Focal therapy has emerged as an integral part of a riskstratified approach to prostate cancer $(\mathrm{CaP})$ treatment in the recent years. Several techniques have now been describedall of them ablative $(1,2)$.

The underlying reason for pursuing focal therapy in $\mathrm{CaP}$ patients is its promise of fewer functional sideeffects without a compromise in oncological control (3). Accordingly, potency and continence results following focal therapy have been encouraging, with approximately $\geq 85 \%$ and $\geq 95 \%$ of the patients potent and continent by 12 months, respectively (4-8). Although oncological outcomes in the short-term appear reassuring (9), given the relative novelty of the focal therapy technology, longterm data on oncological efficacy are lacking. Further, a few limitations of focal ablative technologies have become apparent as experience with them has increased: (I) an inability or reluctance to treat a prostate gland $>40$ gram or apical cancers, (II) an inability to ablate $>60 \%$ of the whole gland, (III) lack of pathological information on the ablated prostatic tissue, and (IV) a high positive biopsy rate $[\sim 50 \%$ clinical significant $\mathrm{CaP}$ (Gleason score 7 or above)] in the residual prostate tissue resulting in a high rate of redo procedures ( $25 \%$ of the patients) within 3 years (6-8).

Building on the collective work of our peers in the field of focal therapy, while hoping to overcome the limitations of the focal ablative techniques, we recently described a novel surgical approach to $\mathrm{CaP}$ focal therapy-the precision prostatectomy. The robotic precision prostatectomy spares a $5-10 \mathrm{~mm}$ rim of prostate tissue unilaterally saving the ipsilateral neurovascular bundle in toto, while removing $>90 \%$ of the gland along with the dominant cancer lesion. We recently reported on the short-term results in the first 8 patients that we had treated using this focal surgical approach $(10,11)$. In this article, we sought to accomplish two goals: First, to provide an update on the safety, and functional and oncological outcomes in the first 25 consecutive men that have undergone precision prostatectomy and have greater than 2 years of followup, and second, to identify men within the Surveillance Epidemiology and End Results (SEER) data-registry that have undergone non-radical/focal treatment (surgical or ablative) for $\mathrm{CaP}$ over the years of registry subsistence, and assess long-term cancer survival outcomes in them. We present the following article in accordance with the STROBE reporting checklist (available at http://dx.doi. org/10.21037/tau-20-1476).

\section{Methods}

\section{Informed consent and study entry criteria for precision prostatectomy}

Men meeting the criteria: (I) PSA $\leq 15 \mathrm{ng} / \mathrm{mL}$, (II) stage $\leq \mathrm{cT} 2$, (III) dominant unilateral lesion with Gleason score $\leq 4+3$ with any number of cores or percentage (\%) cores involved ipsilaterally on TRUS prostate biopsy, (IV) no primary Gleason score $\geq 4$ contralaterally on TRUS prostate biopsy, and (V) preoperatively potent with/without PDE-5 inhibitors were included in this IDEAL stage $2 \mathrm{~b}$ prospective study $(10,11)$.

The patients were apprised of the experimental nature of the intervention, and the fact that the risks could not be accurately estimated given the novelty of the procedure. Patients were required to review the informational material for at least seven days (11) before they would be considered for precision prostatectomy. Failing this inhome evaluation, patients were assigned to conventional radical prostatectomy. Informed consent was obtained from all patients. Data collection was done under an ongoing research protocol approved by the Henry Ford Hospital Institutional Review Board for the prospective trial of image-guided diagnosis and treatment of $\mathrm{CaP}$ (HFHIRB\#12507), and in compliance with HIPAA regulations.

\section{Surgical technique of precision prostatectomy}

Patient positioning, port placement, development of the space of Retzius, bladder neck incision and prostatic pedicle dissection were all performed in a manner similar to that of a traditional anterior approach of robotic radical prostatectomy $(12,13)$. The difference was in the way the nerve-sparing was performed: A conventional nerve-sparing was performed on the side of the dominant cancer lesion, while, on the contralateral side (the precision side), the dissection was started anterior to the vas deferens/seminal vesicle complex, preserving all layers of Denonvilliers' fascia, with the included erectogenic nerves $(14,15)$. The dissection was then continued $5-10 \mathrm{~mm}$ into the prostatic capsule, deliberately attempting to leave behind a thin rim of prostatic capsule/peripheral tissue $(5-10 \mathrm{~mm})$ along with the seminal vesicle/ejaculatory duct complex $(10,11)$. Systematic needle biopsies (via a suprapubic or transperineal approach) were taken from the remnant prostatic tissue, and sent for frozen section analysis. Completion prostatectomy was performed if the frozen biopsies showed residual cancer. Vesicourethral anastomosis was performed as 
previously described $(12,13)$. The patients received a Foley or suprapubic tube per patient choice.

\section{IDEAL stage $2 b$ study of precision prostatectomy: variables, endpoints, follow-up and data analysis}

For each patient, the following clinical characteristics were noted: age, race, body mass index, comorbidities, prior surgical history, preoperative prostate-specific antigen (PSA) level, clinical tumor stage, biopsy Gleason score, total number of cores on biopsy, number of positive cores on biopsy, percentage core positivity and urinary and sexual functional scores (see below). Preoperative patient preferences were recorded utilizing a previously validated 10-point clinical tool (Figure S1) (16). Operative characteristics collected included total operative time, console operative time, estimated blood loss, results of frozen section analysis, intraoperative complications and need to convert to radical prostatectomy. Pathological parameters collected included pathologic Gleason Score, pathological tumor stage and surgical margin status. The prostatectomy specimens were sectioned and processed according to the previously described wholemount methodology by Ruijter et al. (17). Postoperative complications noted included need for blood transfusion, urinary tract infections, lymphoceles, deep venous thrombosis, pulmonary embolus, pneumonia, myocardial infections and death for 90 days after surgery. Preoperative and postoperative urinary and sexual function assessments were performed using the International Prostate Symptom Score (IPSS) and International Index of Erectile Function (IIEF-5 or SHIM) questionnaires. Postoperative PSA was collected at 4, 8 and 12 months. Three separate criteria were used to assess biochemical recurrence (BCR): (I) the American Urological Association (AUA) criteria for BCR following radical prostatectomy (i.e., a single value of PSA $>0.4$ or two consecutive values $>0.2 \mathrm{ng} / \mathrm{mL}$ ) (18) with remnant biopsy confirmation (the remnant biopsy confirmation was sought as a detectable PSA could be the result of residual benign or malignant cells, and histologic verification was required to diagnose BCR from cancer), (II) Phoenix criteria (19), and lastly (III) Huber criteria for focal therapy (20). Kaplan-Meier (KM) analysis was used to generate 3-year BCR, clinically-significant $\mathrm{CaP}$ (ISUP grade group $\geq 2$ ) in the remnant, metastasis, cancer-specific mortality and overall mortality estimates. All patients were followed for at least 24 months.

\section{SEER registry based assessment of non-radical CaP treatment}

The SEER program covers approximately $35 \%$ of the US population, and is one of the most comprehensive source of population-based information in the US that includes stage of cancer at the time of diagnosis, treatment performed, and patient survival data (21). For the current study, data were abstracted from the 18-registry SEER dataset [2004-2015]. Only patients that had a pre-treatment biopsy-proven diagnosis of localized CaP (ICD-O code 61.9, histologic code 8140 ), and subsequently underwent a non-radical treatment for it were included. After excluding patients with missing data, a final sample size of 4,116 patients was obtained. Patients were grouped according to treatment type: hyperthermia, cryotherapy or segmental prostatectomy (22). The outcome of interest was $\mathrm{CaP}$ specific mortality. KM analysis was utilized to assess differences in $\mathrm{CaP}$ specific mortality among the groups and generate 10-year survival estimates. Cox proportional hazards modeling was performed to identify predictors of $\mathrm{CaP}$ specific mortality. The SEER study was approved by the Henry Ford Hospital Institutional Review Board (HFH-IRB\# 13342) and was conducted in accordance with the Declaration of Helsinki (as revised in 2013).

\section{Statistical analysis}

All statistical analyses were performed using SAS 9.3 (SAS Institute, Cary, NC). A two-sided statistical significance was defined as a $\mathrm{P}$ value $<0.05$.

\section{Results}

\section{Baseline characteristics, preferences and operative outcomes} in patients undergoing precision prostatectomy

Table 1 provides details on the baseline characteristics. Twenty-five patients underwent precision prostatectomy successfully during the study-period. One patient, not part of this report, was excluded due to positive intraoperative biopsy necessitating conversion to radical prostatectomy. Median (IQR) age and PSA were 56.5 (53.1-62.3) years and $4.2(3.8-5.9) \mathrm{ng} / \mathrm{mL}$, respectively. All patients were potent preoperatively with a median SHIM score of 23 , however, 5 (20\%) patients were on phosphodiesterase type 5 inhibitors (PDE-5i). Only 1 of the 25 patients (4\%) met the Epstein criteria (23) for active surveillance. 
Table 1 Baseline characteristics in patients undergoing robotic precision prostatectomy between December 2016 and July 2017, $\mathrm{n}=25$

\begin{tabular}{|c|c|}
\hline Patient characteristics & Number \\
\hline Age in years, median (IQR) & $56.5(53.1-62.3)$ \\
\hline \multicolumn{2}{|l|}{ Race, n (\%) } \\
\hline Caucasian & $19(76.0)$ \\
\hline African American & $4(16.0)$ \\
\hline Others & $2(8.0)$ \\
\hline $\mathrm{BMI}$ in $\mathrm{kg} / \mathrm{m}^{2}$, median (IQR) & $29.0(27.2-31.0)$ \\
\hline \multicolumn{2}{|l|}{ Past medical history, n (\%) } \\
\hline Hypertension & $18(72.0)$ \\
\hline Diabetes mellitus & $2(8.0)$ \\
\hline $\begin{array}{l}\text { Coronary artery or cerebrovascular } \\
\text { disease }\end{array}$ & $14(56.0)$ \\
\hline Smoker & $3(12.0)$ \\
\hline Past surgical history ${ }^{\star}, \mathrm{n}(\%)$ & $10(40.0)$ \\
\hline \multicolumn{2}{|l|}{ Prostate cancer characteristics } \\
\hline $\mathrm{PSA}$ in $\mathrm{ng} / \mathrm{mL}$, median (IQR) & $4.2(3.8-5.9)$ \\
\hline \multicolumn{2}{|l|}{ PSA in ng/mL, categorical, $\mathrm{n}(\%)$} \\
\hline$<10$ & $25(100.0)$ \\
\hline $10-20$ & $0(0)$ \\
\hline$>20$ & $0(0)$ \\
\hline Biopsy cores obtained ${ }^{\star \star}$, median (IQR) & $12[12-14]$ \\
\hline \multicolumn{2}{|l|}{ Biopsy Gleason score, n (\%) } \\
\hline $3+3$ & $9(36.0)$ \\
\hline $3+4$ & $15(60.0)$ \\
\hline $4+3$ & $1(4.0)$ \\
\hline$\geq 4+4$ & $0(0)$ \\
\hline \multicolumn{2}{|l|}{ Laterality of disease on biopsy, $\mathrm{n}(\%)$} \\
\hline Unilateral & $17(68.0)$ \\
\hline Bilateral & $8(32.0)$ \\
\hline \multicolumn{2}{|l|}{ Clinical stage, $n(\%)$} \\
\hline$\leq \mathrm{cT} 2 \mathrm{a}$ & $24(96.0)$ \\
\hline cT2b & $1(4.0)$ \\
\hline$\geq \mathrm{cT} 2 \mathrm{c}$ & $0(0)$ \\
\hline $\begin{array}{l}\text { Patients satisfying Epstein Criteria for } \\
\text { Active Surveillance }^{a}, \mathrm{n}(\%)\end{array}$ & $1(4.0)$ \\
\hline
\end{tabular}

Table 1 (continued)
Table 1 (continued)

\begin{tabular}{ll}
\hline Patient characteristics & Number \\
\hline $\begin{array}{l}\text { Estimated prostate size in mL, median } \\
\text { (IQR) }\end{array}$ & $46.5(39-69.8)$ \\
Functional characteristics & \\
SHIM score, median (IQR) & $23[20-25]$ \\
$\quad$ Patients on PDE5i, n (\%) & $5(20.0)$ \\
Patients on ICl, n (\%) & $0(0)$ \\
IPSS composite score, median (IQR) & $4(3-10.5)$ \\
IPSS QoL score, median (IQR) & $1[0-4]$
\end{tabular}

*, past surgeries recorded included colectomy, splenectomy, umbilical hernia repair, inguinal hernia repair, cholecystectomy, appendectomy; **, biopsies were performed transrectally with/without MRI fusion as we had yet not started performing transperineal biopsies at our institution. ${ }^{a}$, patients chose to have focal therapy. IQR, interquartile range; BMI, body mass index; PSA, prostate specific-antigen; SHIM, sexual health inventory for men; PDE5i, phosphodiesterase type-5 inhibitor; $\mathrm{ICI}$, intracavernosal injection; IPSS, International Prostate Symptom Score; QoL, quality of life.

Median (IQR) console time was 133 min (125-141 min). There were no complications intraoperatively but one patient experienced a lymphocele postoperatively (Table 2).

Figure 1 provides the breakdown of the preoperative patient preferences. Cancer control was the top priority for patients in both the radical and precision prostatectomy groups, however, the preferences for functional qualityof-life, especially potency preservation, varied significantly among the two groups.

\section{Oncological and functional outcomes in patients undergoing precision prostatectomy}

All patients were followed for a minimum of 2 years. At 12 months, all (100\%) patients were continent (0-1 pads), with $92 \%(n=23$ of 25$)$ of the patients using 0 pads. The median (IQR) time to urinary continence was 1 month (1-4 months). Twenty-three (92\%) of the 25 patients were potent at 12 months. The median SHIM score was 21 at 12 months with $76 \%$ of the patients using PDE-5i on an asneeded basis (Table 3). The median time to sexual potency was 4 months (4-12 months).

From an oncological standpoint, none $(0 \%)$ of the patients had BCR per the Phoenix or Huber criteria for focal therapy at 36 months $(19,20)$. The median PSA 
Table 2 Operative and immediate postoperative characteristics in patients undergoing robotic precision prostatectomy between December 2016 and July 2017, n=25

\begin{tabular}{|c|c|}
\hline Operative and postoperative characteristics & Number \\
\hline Operative time in minutes, median (IQR) & 189 [164-199] \\
\hline Console time in minutes, median (IQR) & $133[125-141]$ \\
\hline Estimated blood Loss in $\mathrm{mL}$, median (IQR) & $112[100-150]$ \\
\hline \multicolumn{2}{|l|}{ Precision prostatectomy laterality, $\mathrm{n}(\%)$} \\
\hline Left & $11(44.0)$ \\
\hline Right & $14(56.0)$ \\
\hline \multicolumn{2}{|l|}{ Type of nerve sparing on the radical side, $\mathrm{n}(\%)$} \\
\hline Veil & $13(52.0)$ \\
\hline Standard & $12(48.0)$ \\
\hline Wide & $0(0)$ \\
\hline \multicolumn{2}{|l|}{ Intra-op capsular biopsy details } \\
\hline Performed yes, n (\%) & $23(92.0)$ \\
\hline No. of biopsy cores taken, median (IQR) & $8[5-10]$ \\
\hline \multicolumn{2}{|l|}{ Results of the intra-op biopsy*, n (\%) } \\
\hline Atypia & $3(12.0)$ \\
\hline Benign prostatic hyperplasia & $20(80.0)$ \\
\hline Fibromuscular tissue & $0(0)$ \\
\hline NA (biopsy not performed) & $2(8.0)$ \\
\hline Lymph nodes removed ${ }^{\star \star}$, median (IQR) & $8[4-12]$ \\
\hline Length of stay in days, median (IQR) & $1[1-1]$ \\
\hline Inpatient complications^, n (\%) & $0(0)$ \\
\hline 3-month complications^, n (\%) & $1(4.0)$ \\
\hline
\end{tabular}

*, patients that had a positive result on the intra-op biopsy were converted to standard radical prostatectomy $(n=0) ;{ }^{* *}, 4$ patients did not have LNs removed; $\wedge$, complications captured were acute blood loss anemia, UTI, epididymitis, surgical site infections, wound dehiscence, DVT/PE, MI, pneumonia, lymphocele and return-to-OR for any reason; the 1 patient that experienced complication developed a lymphocele. Intra-op biopsies were performed with either transperineally or suprapubically; suprapubic biopsies were performed via a 14- or 16-Gauge angiocath passed through the suprapubic region, through which an 18-Gauge Bard biopsy needle was passed and cores obtained under visual guidance via the robotic camera. IQR, interquartile range.

was $0.1 \mathrm{ng} / \mathrm{mL}$ post-surgery at 12 and 24 months followup. Given the novelty of our procedure and the lack of guidelines regarding oncological follow-up, we also assessed
BCR in these patients using the AUA criteria for wholegland radical prostatectomy coupled with remnant biopsy confirmation: 4 patients (36-month KM-estimate: $17.4 \%$ ) had BCR per this criterion. Three patients had Gleason $3+3$ disease while 1 patient had Gleason $3+4$ disease in the remnant. Two patients including the patient with Gleason $3+4$ disease had remnant removal surgery (36-month KMestimate: $7.3 \%$ ), while the other 2 chose active surveillance. It is interesting to note that surgical margin status was not associated with BCR ( $\mathrm{P}=0.661)$ - of the 4 patients who experienced BCR, 1 had a positive margin on both sides, 1 only on the precision prostatectomy side, and 2 had negative margins. Of the 21 patients who did not experience BCR per the AUA criteria, 5 had undetectable PSA and declined a protocol biopsy, while the remaining 16 patients had no evidence of cancer on the biopsy of the remnant (median cores taken, 7). At 36 months, all patients were alive and free of metastatic disease (Table 3).

\section{Baseline and long-term oncological data from the SEER data-registry on focal therapies}

Table 4 provides details on the baseline characteristics. Of the 4,116 patients that underwent non-radical treatment of $\mathrm{CaP}$ during the 12-year study-period, $4.1 \% \quad(n=169)$ underwent hyperthermia, $86.8 \%(n=3,571)$ cryotherapy, and the remaining $9.1 \%(n=376)$ segmental prostatectomy. Patients undergoing segmental prostatectomy were of younger age compared to other groups $(\mathrm{P}<0.001)$. Patients treated with segmental prostatectomy had higher pretreatment PSA levels, with $12.2 \%$ of patients having a value $>20 \mathrm{ng} / \mathrm{mL}$, compared to $4.7 \%$ and $5.7 \%$ of the patients treated with hyperthermia and cryotherapy, respectively $(\mathrm{P}<0.001)$. On the other hand, segmental prostatectomy patients had lower biopsy Gleason scores, with only $9.6 \%$ of patients having a Gleason score $\geq 8$, compared to $13.6 \%$ and $14.3 \%$ of the patients in hyperthermia and cryotherapy groups, respectively ( $\mathrm{P}<0.001)$. Overall, 28.9\%, 40.4\% and $39.1 \%$ of the patients undergoing hyperthermia, cryotherapy and segmental prostatectomy were D'Amico high-risk $(\mathrm{P}=0.003)$.

The median follow-up in the 3 treatment groupshyperthermia, cryotherapy and segmental prostatectomywas 7.4, 6.2 and 5.4 years, respectively. Figure 2 provides 10-year CaP-specific mortality estimates for the 3 treatment groups: overall, and stratified by D'Amico risk categories. In the overall cohort, at 10 years, $2.3 \%, 8.4 \%$ and $4.6 \%$ had died of $\mathrm{CaP}$ in hyperthermia, cryotherapy and segmental 


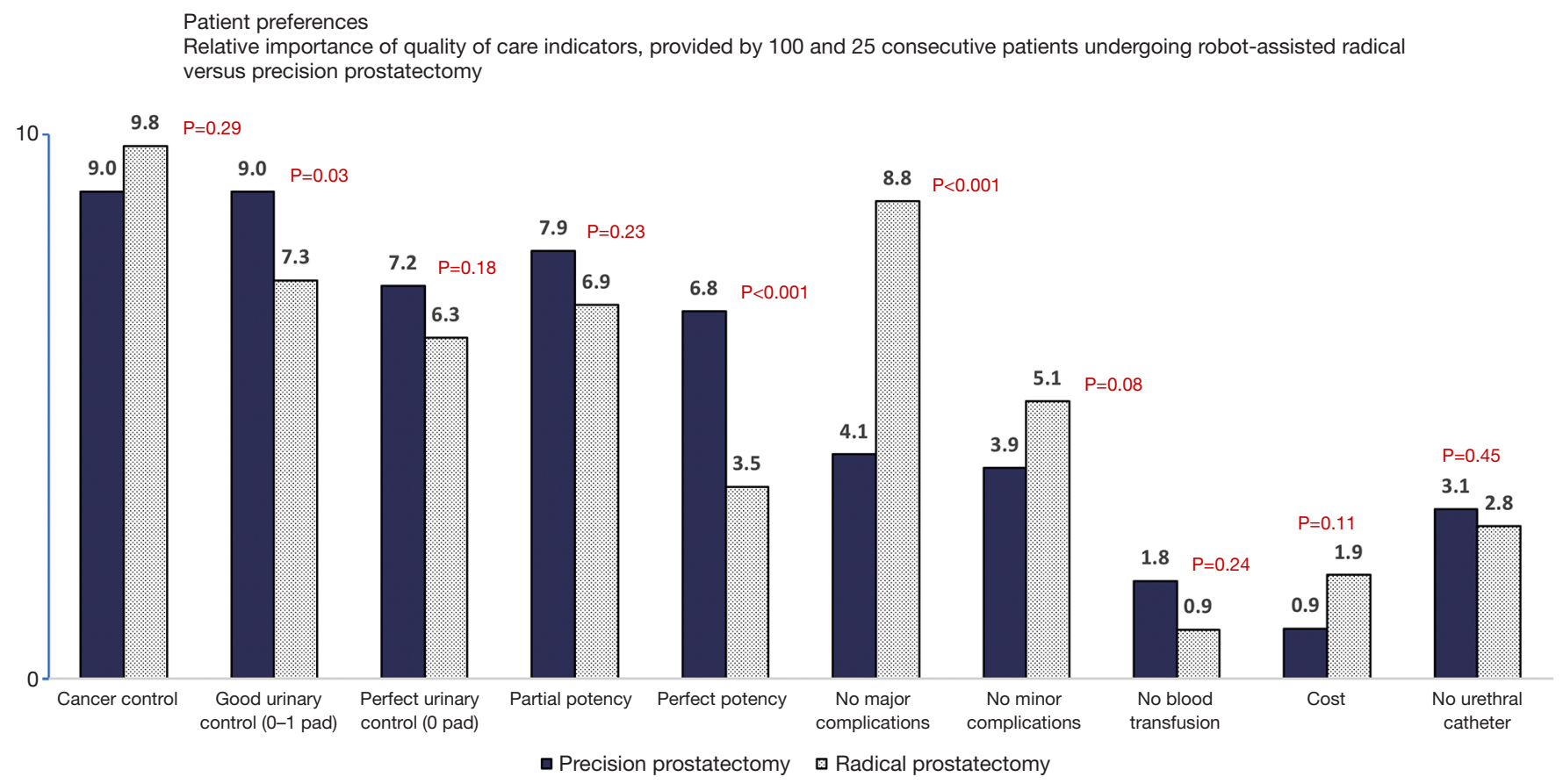

Figure 1 Preoperative rankings of the relative importance of the 10 mutually exclusive quality-of-care indicators, provided by $100^{*}$ and 25 consecutive patients undergoing robot-assisted radical prostatectomy and precision prostatectomy, respectively. The 10 questions are mutually exclusive, that is a patient can only assign a score of 10 (highest score) to one item, and then the next item, in order of priority, will receive a score of 9 , and so on; *, the 100 patients reported here for radical prostatectomy fulfilled the criteria for focal therapy but decided to undergo radical treatment (data on clinical and pathological details of these patients not shown [available in ref (10)].

prostatectomy groups, respectively. These results did not attain statistical significance, Log-rank $\mathrm{P}=0.298$ (Figure 2A). In the D'Amico risk based sub-group analysis: similarly, no differences were seen in 10-year $\mathrm{CaP}$ death rates among the treatment groups.

Cox regression analysis revealed older age, advanced clinical stage, and higher pre-treatment PSA levels and biopsy scores to be associated with worse survival. The type of focal therapy was not associated with CaP-specific mortality (Table 5).

\section{Conclusions}

Whole-gland treatment of localized $\mathrm{CaP}$ is associated with significant functional side-effects, in particular erectile dysfunction $(24,25)$. In an attempt to minimize this, focal $\mathrm{CaP}$ ablative techniques have recently been developed $(1,2)$ following the well-established organ-preserving treatment paradigms in other malignancies (26-29).

Reports on focal ablative therapies have demonstrated promising functional outcomes, however, concerns regarding high secondary procedure rates and clinicallysignificant residual cancer have hampered the adoption (6-8). A study of 150 men ( $n=145 \geq$ Gleason 7$)$ undergoing partial gland HIFU (high-intensity focused ultrasound) by Bass et al showed residual cancer in $70.5 \%$ of the men who underwent confirmatory biopsy and a $25 \%$ re-treatment rate, despite an attempt to ablate 5-10 fold the lesion volume detected on mp-MRI (6). It should be further noted that over $50 \%$ of these positive biopsies were in the areas that had been 'treated'. Similarly, a study of focal HIFU by Mortezavi et al. demonstrated a residual cancer rate of $55.9 \%$, with $75 \%$ of these patients harboring clinicallysignificant $\mathrm{CaP}$ (7). The median follow-up in these studies was limited, between 6 and 14 months. We have previously reasoned and demonstrated via our IDEAL stage 0 studies $(10,11)$ that the reason for high residual cancer rates after focal, partial or hemigland HIFU or other ablative treatments is the inherent multifocality of cancer foci within the prostate, coupled with the fact that that $\mathrm{mp}$ MRI technology cannot detect lesions smaller than $0.5 \mathrm{cc}$ (whether high or low Gleason grade) (30) and focal ablative 
Table 3 Oncological and functional outcomes in patients undergoing robotic precision prostatectomy between December 2016 and July 2017, $\mathrm{n}=25$

\begin{tabular}{|c|c|}
\hline Variables & Number \\
\hline \multicolumn{2}{|l|}{ Oncological outcomes } \\
\hline Prostate weight in grams, median (IQR) & $36.7(29-73.1)$ \\
\hline \multicolumn{2}{|l|}{ Pathologic T stage, n (\%) } \\
\hline$\leq \mathrm{pT} 2 \mathrm{a}$ & $5(20.0)$ \\
\hline pT2b & $0(0)$ \\
\hline pT2c & $19(76.0)$ \\
\hline pT3a & $1(4.0)$ \\
\hline \multicolumn{2}{|l|}{ Pathologic N stage, n (\%) } \\
\hline pNO & $21(84.0)$ \\
\hline pN1 & $0(0)$ \\
\hline $\mathrm{pNx}$ & $4(16.0)$ \\
\hline \multicolumn{2}{|l|}{ Pathologic Gleason score, n (\%) } \\
\hline $3+3$ & $4(16.0)$ \\
\hline $3+4$ & $18(72.0)$ \\
\hline $4+3$ & $2(8.0)$ \\
\hline$\geq 4+4$ & $1(4.0)$ \\
\hline \multicolumn{2}{|l|}{ Surgical margins details } \\
\hline \multicolumn{2}{|l|}{ Positivity rate, $\mathrm{n}(\%)$} \\
\hline On the PP side ${ }^{\star}$ & $6(24.0)$ \\
\hline On the radical side* & $3(12.0)$ \\
\hline Both sides* & $2(8.0)$ \\
\hline \multicolumn{2}{|l|}{ PSA in ng/mL, median (IQR) } \\
\hline At 12 months & $0.1(0.0-0.45)$ \\
\hline At 24 months & $0.1(0.0-0.50)$ \\
\hline \multicolumn{2}{|l|}{$\begin{array}{l}\text { Biochemical recurrence free survival } \\
\text { rates at } 36 \text { months }^{\text {ab }}\end{array}$} \\
\hline Per Phoenix criteria, \% (95\% Cl) & $100.0(\mathrm{NA})$ \\
\hline Per Huber criteria, \% (95\% Cl) & $100.0(\mathrm{NA})$ \\
\hline $\begin{array}{l}\text { Per AUA RP criteria with postoperative } \\
\text { biopsy confirmation, } \%(95 \% \mathrm{Cl})\end{array}$ & $82.6(76.1-90.5)$ \\
\hline $\begin{array}{l}\text { Clinically significant CaP free survival } \\
\text { rate at } 36 \text { months in } \%(95 \% \mathrm{Cl})^{\mathrm{b}}\end{array}$ & $96.2(92.9-98.7)$ \\
\hline $\begin{array}{l}\text { Radical treatment free survival rate at } \\
36 \text { months in \% }(95 \% \mathrm{Cl})^{\mathrm{b}}\end{array}$ & $92.7(88.9-97.2)$ \\
\hline
\end{tabular}

Table 3 (continued)
Table 3 (continued)

\begin{tabular}{|c|c|}
\hline Variables & Number \\
\hline $\begin{array}{l}\text { Metastatic disease rate at } 36 \text { months in } \\
\%(95 \% \mathrm{Cl})^{\mathrm{b}}\end{array}$ & $0(0)$ \\
\hline $\begin{array}{l}\text { Cancer-specific mortality rate at } 36 \\
\text { months in } \%(95 \% \mathrm{Cl})^{\mathrm{b}}\end{array}$ & $0(0)$ \\
\hline $\begin{array}{l}\text { Overall mortality rate at } 36 \text { months in \% } \\
(95 \% \mathrm{Cl})^{\mathrm{b}}\end{array}$ & $0(0)$ \\
\hline \multicolumn{2}{|l|}{ Functional outcomes } \\
\hline SHIM score at 12 months, median (IQR) & $21(19-23.5)$ \\
\hline Patients on PDE5i at 12 months, $\mathrm{n}(\%)$ & $19(76.0)$ \\
\hline Patients on $\mathrm{ICl}$ at 12 months, $\mathrm{n}(\%)$ & $2(12.0)$ \\
\hline Urinary Continent at 12 months, $\mathrm{n}(\%)$ & $25[100]$ \\
\hline \multicolumn{2}{|c|}{$\begin{array}{l}\text { *, of the } 6 \text { positive surgical margins on the MPP side, } 5 \text { were } G \\
3+3 \text { and } 1 \text { was } G 3+4 \text {; of the } 3 \text { positive surgical margins on the } \\
\text { radical side, } 1 \text { was } \mathrm{G} 3+3 \text { and } 2 \text { were } \mathrm{G} 3+4 \text {; of the } 2 \text { positive } \\
\text { surgical margins on both sides, both were } \mathrm{G} 3+4 \text {. }^{\text {a }} \text {, Phoenix } \\
\text { criteria has been defined as nadir }+2 \mathrm{ng} / \mathrm{mL} \text { and Huber criteria } \\
\text { has been defined as nadir }+1.5 \mathrm{ng} / \mathrm{mL} \text { at } 2-3 \text { years. }{ }^{b} \text {, Kaplan- } \\
\text { Meier estimates with } 95 \% \mathrm{Cl} \text {. IQR, interquartile range; PP, } \\
\text { precision prostatectomy; RP, radical prostatectomy. }\end{array}$} \\
\hline
\end{tabular}

techniques spare $5-10 \mathrm{~mm}$ of peripheral tissue on the treatment side and do not treat the contralateral peripheral zone (4,6-8). It seems logical that by maximizing prostatic extirpation, the failure rates may be minimized [see Figure 1 of (10)], and a more acceptable balance may be achieved between the functional quality-of-life preservation and oncological control.

Accordingly, in the present study, we demonstrated that at 12 months, all patients were continent and $92 \%$ of the patients were potent, and at 36 months, $96.2 \%$ and $92.7 \%$ of the patients were free from clinically-significant $\mathrm{CaP}$ and radical treatment, respectively. All patients were alive and free of metastatic disease at study conclusion. However this evaluation of our technique is not devoid of limitations, within the bounds of which our results should be interpreted. These limitations include single-center design, and lack of long-term follow-up. However, the goal of this paper was to report on early results of the technique especially the functional results. Another limitation of our study is that patients selected for precision prostatectomy did not routinely undergo mp-MRI imaging, PSMA-PET imaging, or saturation biopsies to better characterize the burden and topography of $\mathrm{CaP}$ within the gland. Although 
Table 4 Baseline characteristics in patients with prostate cancer undergoing non-radical treatment (ablative or surgical); SEER registry data 2004-2015 (n=4,116)

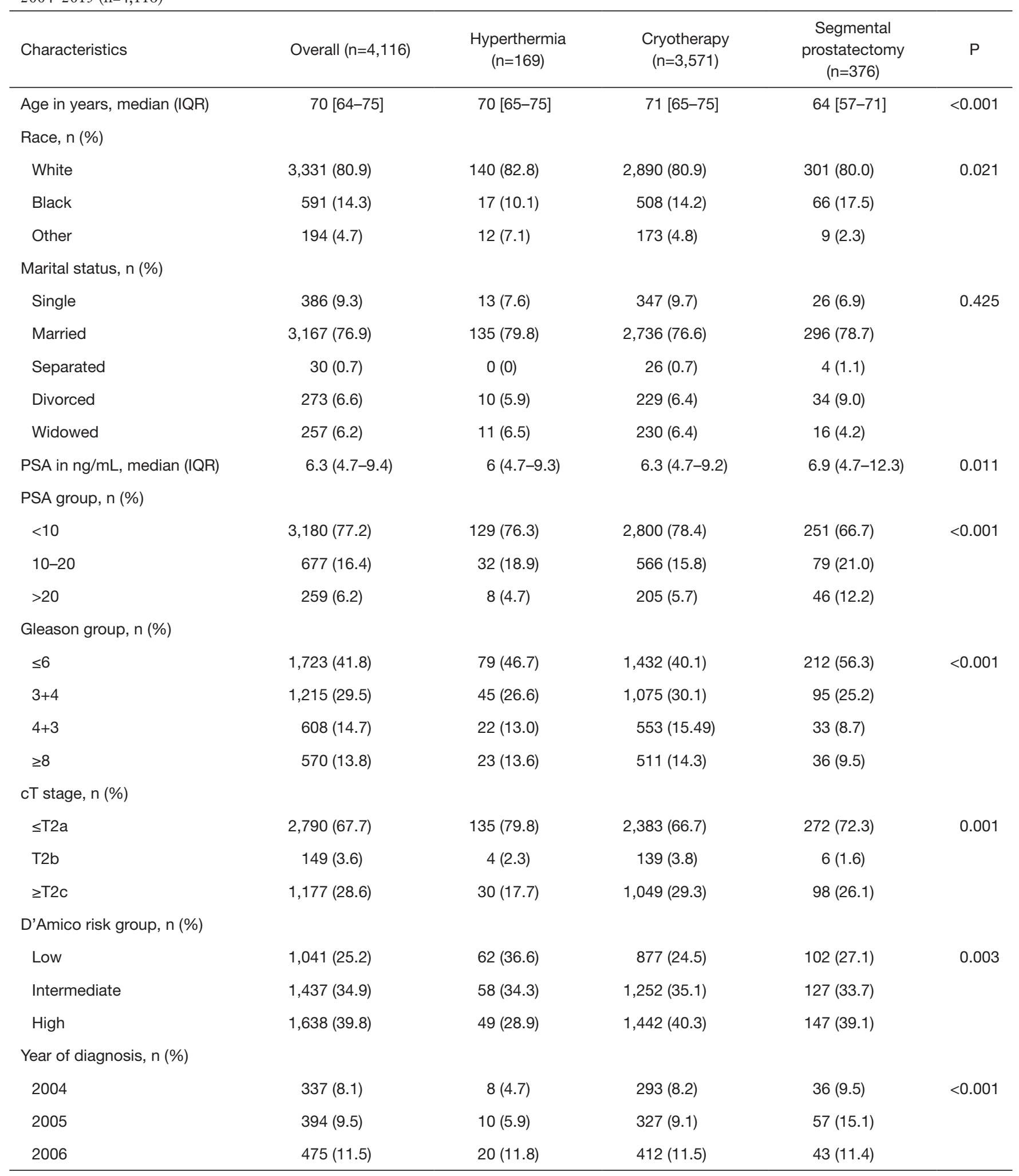

Table 4 (continued) 
Table 4 (continued)

\begin{tabular}{lllll}
\hline Characteristics & Overall $(\mathrm{n}=4,116)$ & $\begin{array}{c}\text { Hyperthermia } \\
(\mathrm{n}=169)\end{array}$ & $\begin{array}{c}\text { Cryotherapy } \\
(\mathrm{n}=3,571)\end{array}$ & $\begin{array}{c}\text { Segmental } \\
\text { prostatectomy } \\
(\mathrm{n}=376)\end{array}$ \\
\hline 2007 & $549(13.3)$ & $37(21.8)$ & $483(13.5)$ & $29(7.7)$ \\
2008 & $488(11.8)$ & $44(26.0)$ & $415(11.6)$ & $29(7.7)$ \\
2009 & $381(9.2)$ & $16(9.4)$ & $343(9.6)$ & $22(5.8)$ \\
2010 & $342(8.3)$ & $9(5.3)$ & $313(8.7)$ & $20(5.3)$ \\
2011 & $354(8.6)$ & $7(4.1)$ & $322(9.0)$ & $25(6.6)$ \\
2012 & $245(5.9)$ & $1(0.5)$ & $211(5.9)$ & $33(8.7)$ \\
2013 & $235(5.7)$ & $6(3.5)$ & $206(5.7)$ & $23(6.1)$ \\
2014 & $171(4.1)$ & $9(5.3)$ & $140(3.9)$ & $22(5.8)$ \\
2015 & $145(3.5)$ & $2(1.1)$ & $106(2.9)$ & $37(9.8)$ \\
\hline
\end{tabular}

A

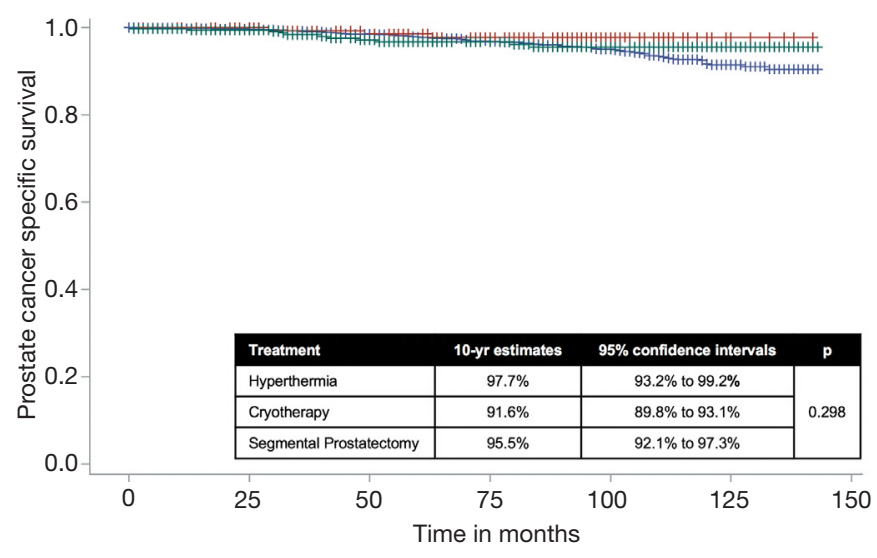

C

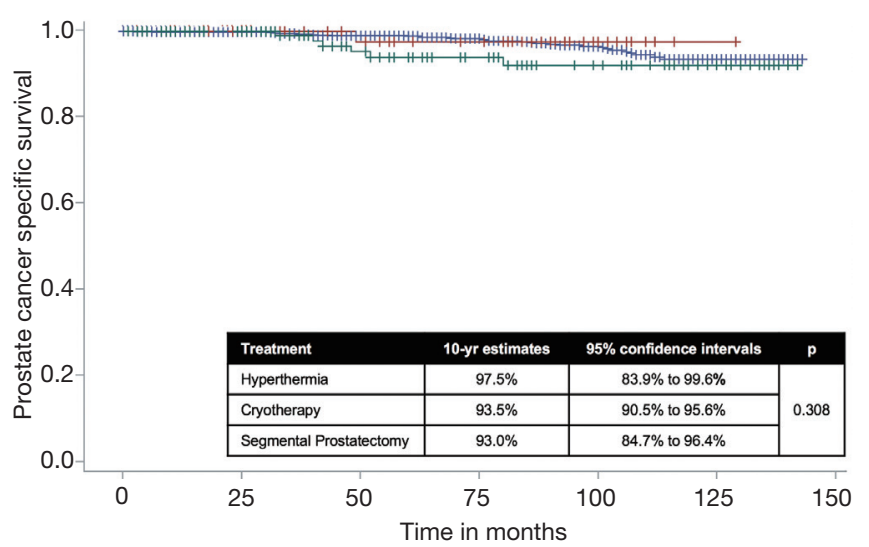

B

LOW-RISK

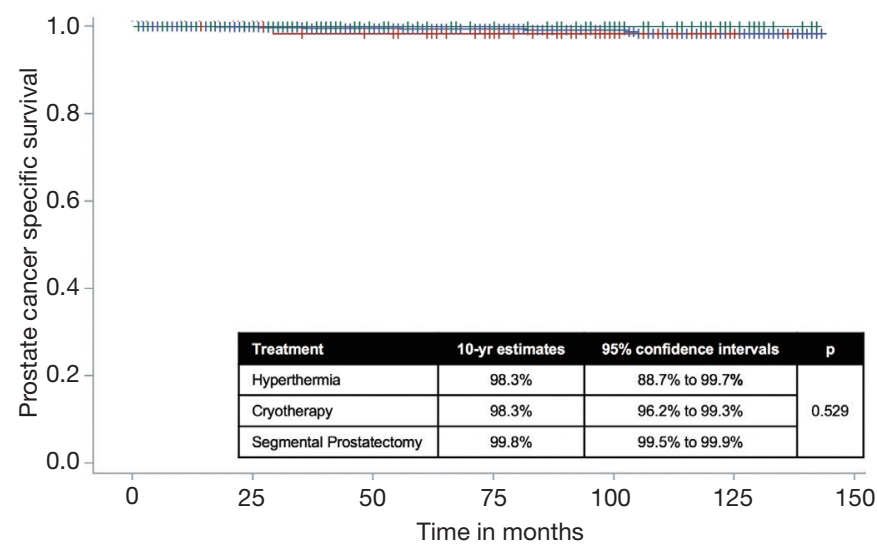

D

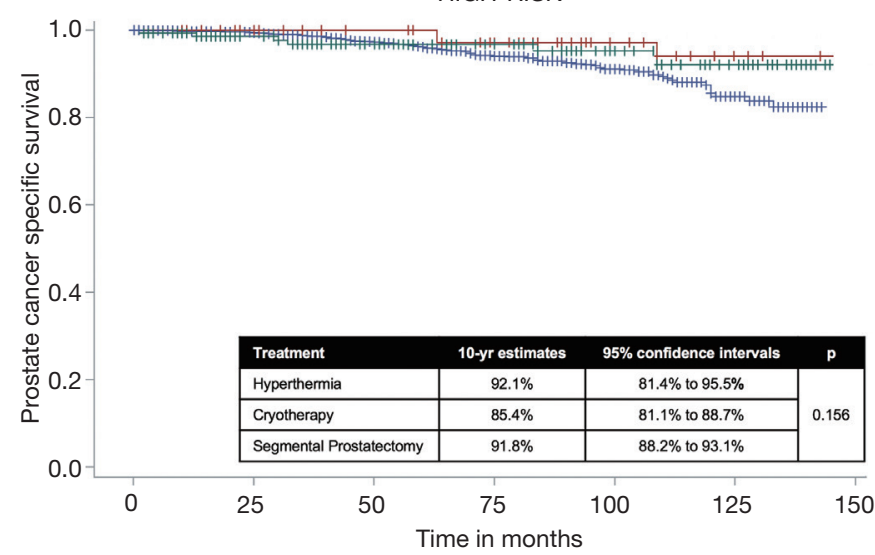

Figure 2 Kaplan-Meier plots of prostate cancer specific survival (A) overall, (B) D'Amico low-risk, (C) D'Amico intermediate-risk and (D) D'Amico high-risk. Red line denotes hyperthermia, blue line denotes cryotherapy, and the green line denotes segmental prostatectomy. 
Table 5 Cox proportional hazards model evaluating predictors of cancer specific mortality in patients with prostate cancer undergoing nonradical treatment (ablative or surgical); SEER registry data 2004-2015 ( $\mathrm{n}=4,116)$; the model adjusted for age, race, year of diagnosis, prostatespecific antigen, clinical stage, Gleason score and type of treatment*

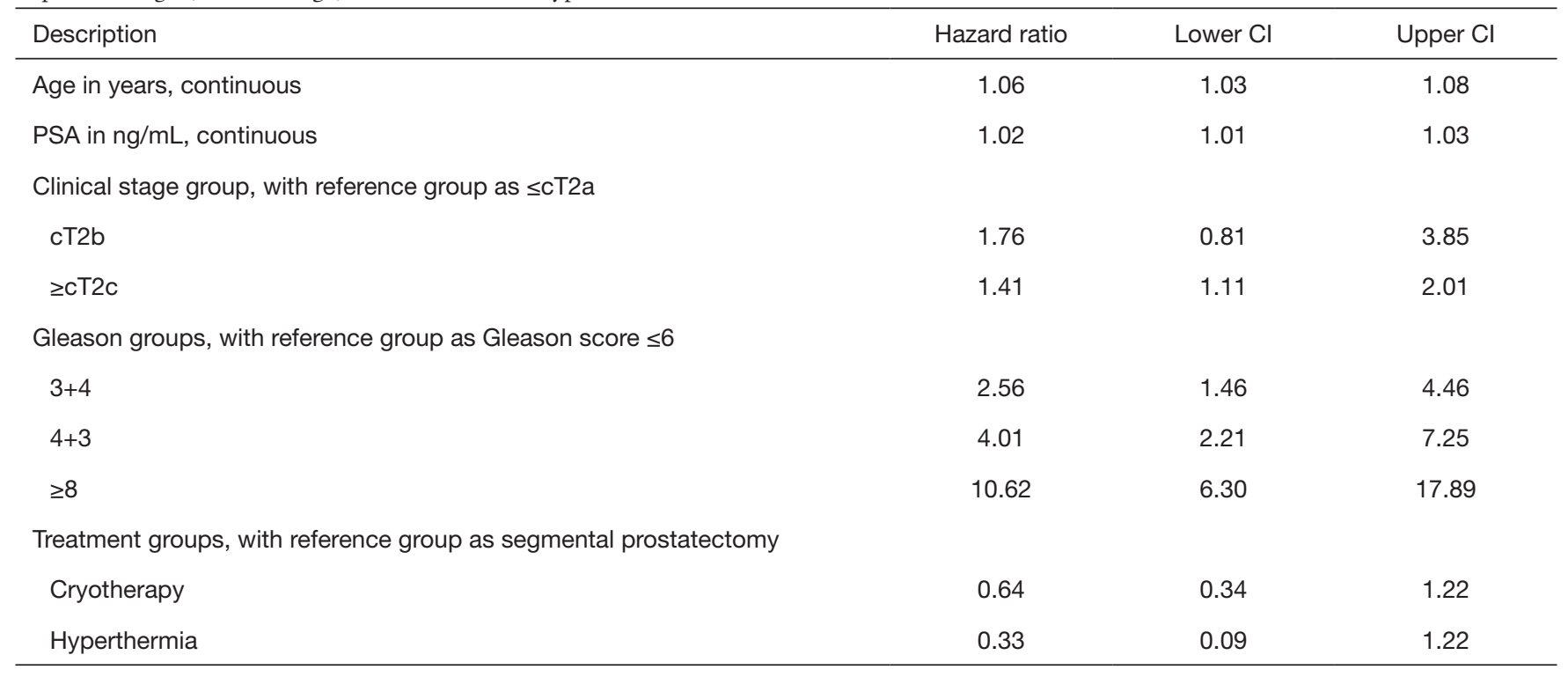

*, race and year of diagnosis were not significant predictors of cancer specific mortality (data not shown in the table).

this lack of standardization is a drawback of our current study, it is also an opportunity for further improvement of our oncological outcomes in the future.

We supplemented our IDEAL stage $2 \mathrm{~b}$ study results with an assessment of 10 -year CaP-specific survival data from the SEER data-registry. We postulated that this examination will help provide answers regarding longterm oncological efficacy of focal therapy treatments, while follow-up data from ongoing prospective studies of focal therapy mature. The findings were rather surprising, and demonstrated good long-term oncological efficacy for focal therapy techniques, with 10 -year CaP-specific mortality rates of $2.5 \%$ to $7 \%$ for intermediate-risk CaP. It is important to point out here that the $\mathrm{CaP}$ patients included in the SEER study were diagnosed with $\mathrm{CaP}$ pre-treatment via prostate biopsy, and do not represent men with incidentally detected $\mathrm{CaP}$ post-treatment (such as after segmental prostatectomy). This suggests that these procedures were undertaken with a curative intent. Why a non-radical treatment was sought can only be speculated, but it does not impair the relevance of findings. While care must be taken when interpreting the results of this study, as the SEER registry does not provide information on additional treatments that these patients may have undergone subsequent to the initial treatment, it is unlikely that patients in the low and intermediate risk categories would have undergone subsequent salvage treatments given the fact that these patients chose to have non-radical treatment in the first place. These findings are further supported by a recent report evaluating short-term outcomes of HIFU - the study noted a 5-year CaP-specific survival rate of $100 \%$ for men with low and intermediate risk $\mathrm{CaP}(9)$. It thus seems plausible that focal treatment of the dominant lesion or the index lesion (31-33) may be all that is needed in some $\mathrm{CaP}$ patients, and a risk-stratified surgical approach to $\mathrm{CaP}$ treatment may be reasonable, especially in men who place a high emphasis on their sexual function. The key is to identify these patients accurately, and to maximize prostatic tissue extirpation without compromising the integrity of the neurovascular tissue.

In the end, only the long-term data will demonstrate the true efficacy of focal therapy. As Yogi Berra said "It's hazardous to make predictions, especially about the future". However, if focal therapy does deliver on its promise in the long-term, it will be a major advance in how care is delivered to $\mathrm{CaP}$ patients.

\section{Acknowledgments}

Funding: None. 


\section{Footnote}

Provenance and Peer Review: This article was commissioned by the Guest Editors (Badrinath R. Konety, Daniel W. Lin) for the series "Current and Future Topics on Prostate Cancer" published in Translational Andrology and Urology. The article has undergone external peer review.

Reporting Checklist: The authors have completed the STROBE reporting checklist. Available at http://dx.doi. org/10.21037/tau-20-1476

Peer Review File: Available at http://dx.doi.org/10.21037/ tau-20-1476

Conflicts of Interest: All authors have completed the ICMJE uniform disclosure form (available at http://dx.doi. org/10.21037/tau-20-1476). The series "Current and Future Topics on Prostate Cancer" was commissioned by the editorial office without any funding or sponsorship. The authors have no other conflicts of interest to declare.

Ethical Statement: The authors are accountable for all aspects of the work in ensuring that questions related to the accuracy or integrity of any part of the work are appropriately investigated and resolved. Informed consent was obtained from all patients. The SEER study was approved by the Henry Ford Hospital Institutional Review Board (HFH-IRB\# 13342). The study was conducted in accordance with the Declaration of Helsinki (as revised in 2013).

Open Access Statement: This is an Open Access article distributed in accordance with the Creative Commons Attribution-NonCommercial-NoDerivs 4.0 International License (CC BY-NC-ND 4.0), which permits the noncommercial replication and distribution of the article with the strict proviso that no changes or edits are made and the original work is properly cited (including links to both the formal publication through the relevant DOI and the license). See: https://creativecommons.org/licenses/by-nc-nd/4.0/.

\section{References}

1. van der Poel HG, van den Bergh RCN, Briers E, et al. Focal Therapy in Primary Localised Prostate Cancer: The European Association of Urology Position in 2018. Eur Urol 2018;74:84-91.
2. Valerio M, Ahmed HU, Emberton M, et al. The role of focal therapy in the management of localised prostate cancer: a systematic review. Eur Urol 2014;66:732-51.

3. Ahmed HU. The index lesion and the origin of prostate cancer. N Engl J Med 2009;361:1704-6.

4. Ahmed HU, Hindley RG, Dickinson L, et al. Focal therapy for localised unifocal and multifocal prostate cancer: a prospective development study. Lancet Oncol 2012;13:622-32.

5. Golan R, Bernstein AN, McClure TD, et al. Partial Gland Treatment of Prostate Cancer Using High-Intensity Focused Ultrasound in the Primary and Salvage Settings: A Systematic Review. J Urol 2017;198:1000-9.

6. Bass R, Fleshner N, Finelli A, et al. Oncologic and Functional Outcomes of Partial Gland Ablation with High Intensity Focused Ultrasound for Localized Prostate Cancer. J Urol 2019;201:113-9.

7. Mortezavi A, Krauter J, Gu A, et al. Extensive Histological Sampling following Focal Therapy of Clinically Significant Prostate Cancer with High Intensity Focused Ultrasound. J Urol 2019;202:717-24.

8. Abreu AL, Peretsman S, Iwata A, et al. High Intensity Focused Ultrasound Hemigland Ablation for Prostate Cancer: Initial Outcomes of a United States Series. J Urol 2020;204:741-7.

9. Guillaumier S, Peters M, Arya M, et al. A Multicentre Study of 5-year Outcomes Following Focal Therapy in Treating Clinically Significant Nonmetastatic Prostate Cancer. Eur Urol 2018;74:422-9.

10. Sood A, Jeong W, Taneja K, et al. The Precision Prostatectomy: an IDEAL Stage 0, 1 and 2a Study. BMJ Surg Interv Health Technologies 2019;1:e000002.

11. Sood A, Abdollah F, Jeong W, et al. The Precision Prostatectomy: "Waiting for Godot". Eur Urol Focus 2020;6:227-30.

12. Menon M, Shrivastava A, Kaul S, et al. Vattikuti Institute prostatectomy: contemporary technique and analysis of results. Eur Urol 2007;51:648-57; discussion 657-8.

13. Ghani KR, Trinh QD, Menon M. Vattikuti Institute Prostatectomy-Technique in 2012. J Endourol 2012;26:1558-65.

14. Clarebrough EE, Challacombe BJ, Briggs C, et al. Cadaveric analysis of periprostatic nerve distribution: an anatomical basis for high anterior release during radical prostatectomy? J Urol 2011;185:1519-25.

15. Costello AJ, Brooks M, Cole OJ. Anatomical studies of the neurovascular bundle and cavernosal nerves. BJU Int 2004;94:1071-6. 
16. Sammon J, Trinh QD, Menon M. Robotic radical prostatectomy: a critical analysis of surgical quality. Curr Opin Urol 2011;21:195-9.

17. Ruijter E, van Leenders G, Miller G, et al. Errors in histological grading by prostatic needle biopsy specimens: frequency and predisposing factors. J Pathol 2000;192:229-33.

18. Thompson IM, Valicenti RK, Albertsen P, et al. Adjuvant and salvage radiotherapy after prostatectomy: AUA/ ASTRO Guideline. J Urol 2013;190:441-9.

19. Roach M 3rd, Hanks G, Thames H Jr, et al. Defining biochemical failure following radiotherapy with or without hormonal therapy in men with clinically localized prostate cancer: recommendations of the RTOG-ASTRO Phoenix Consensus Conference. Int J Radiat Oncol Biol Phys 2006;65:965-74.

20. Huber PM, Afzal N, Arya M, et al. Prostate Specific Antigen Criteria to Diagnose Failure of Cancer Control following Focal Therapy of Nonmetastatic Prostate Cancer Using High Intensity Focused Ultrasound. J Urol 2020;203:734-42.

21. NCI. Surveillance, Epidemiology, and End Results (SEER) Program (www.seer.cancer.gov) SEER*Stat Database: Incidence - SEER 9 Regs Research Data, Nov 2018 Sub $(1975-2016)<$ Katrina/Rita Population Adjustment> Linked To County Attributes - Total U.S., 1969-2017 Counties, National Cancer Institute, DCCPS, Surveillance Research Program, released April 2019, based on the November 2018 submission. 2019.

22. Roy S, Morgan SC. Who Dies From Prostate Cancer? An Analysis of the Surveillance, Epidemiology and End Results Database. Clin Oncol (R Coll Radiol) 2019;31:630-6.

23. Dall'Era MA, Albertsen PC, Bangma C, et al. Active surveillance for prostate cancer: a systematic review of the literature. Eur Urol 2012;62:976-83.

24. Barocas DA, Alvarez J, Resnick MJ, et al. Association Between Radiation Therapy, Surgery, or Observation for Localized Prostate Cancer and Patient-Reported

Cite this article as: Sood A, Jeong W, Keeley J, Abdollah F, Hassan O, Gupta N, Menon M. Subtotal surgical therapy for localized prostate cancer: a single-center precision prostatectomy experience in 25 patients, and SEER-registry data analysis. Transl Androl Urol 2021;10(7):3155-3166. doi: $10.21037 /$ tau-20-1476
Outcomes After 3 Years. JAMA 2017;317:1126-40.

25. Capogrosso P, Vertosick EA, Benfante NE, et al. Are We Improving Erectile Function Recovery After Radical Prostatectomy? Analysis of Patients Treated over the Last Decade. Eur Urol 2019;75:221-8.

26. Fisher B, Anderson S, Bryant J, et al. Twenty-year followup of a randomized trial comparing total mastectomy, lumpectomy, and lumpectomy plus irradiation for the treatment of invasive breast cancer. $\mathrm{N}$ Engl J Med 2002;347:1233-41.

27. Vaidya JS, Joseph DJ, Tobias JS, et al. Targeted intraoperative radiotherapy versus whole breast radiotherapy for breast cancer (TARGIT-A trial): an international, prospective, randomised, non-inferiority phase 3 trial. Lancet 2010;376:91-102.

28. Van Poppel H, Da Pozzo L, Albrecht W, et al. A prospective, randomised EORTC intergroup phase 3 study comparing the oncologic outcome of elective nephronsparing surgery and radical nephrectomy for low-stage renal cell carcinoma. Eur Urol 2011;59:543-52.

29. Bissada NK, Yakout HH, Fahmy WE, et al. Multiinstitutional long-term experience with conservative surgery for invasive penile carcinoma. J Urol 2003;169:500-2.

30. Bratan F, Melodelima C, Souchon R, et al. How accurate is multiparametric MR imaging in evaluation of prostate cancer volume? Radiology 2015;275:144-54.

31. Liu W, Laitinen $S$, Khan $S$, et al. Copy number analysis indicates monoclonal origin of lethal metastatic prostate cancer. Nat Med 2009;15:559-65.

32. Guo CC, Wang Y, Xiao L, et al. The relationship of TMPRSS2-ERG gene fusion between primary and metastatic prostate cancers. Hum Pathol 2012;43:644-9.

33. Cooper CS, Eeles R, Wedge DC, et al. Analysis of the genetic phylogeny of multifocal prostate cancer identifies multiple independent clonal expansions in neoplastic and morphologically normal prostate tissue. Nat Genet 2015;47:367-72. 


\section{Pre-Operative Assessment of Personalized Treatment Priorities}

Please rank the following surgical outcomes by your personal priority, 10 being your highest priority. There is no right answer. You may only select a single 10 , a single 9 , a single 8 etc.

\section{Continence:}

A- Absence of total incontinence

$\begin{array}{llllllllll}1 & 2 & 3 & 4 & 5 & 6 & 7 & 8 & 9 & 10\end{array}$

B- Complete urinary control (noleakage)

$\begin{array}{llllllllll}1 & 2 & 3 & 4 & 5 & 6 & 7 & 8 & 9 & 10\end{array}$

Safety of the operation

A- No major complications (eg.heart attack, kidney failure, need for reoperation)

$\begin{array}{llllllllll}1 & 2 & 3 & 4 & 5 & 6 & 7 & 8 & 9 & 10\end{array}$

B- No minor complications (eg. prolonged catheterization, urinary tract infection)

$\begin{array}{llllllllll}1 & 2 & 3 & 4 & 5 & 6 & 7 & 8 & 9 & 10\end{array}$

Cancer Control / No Biochemical Recurrence

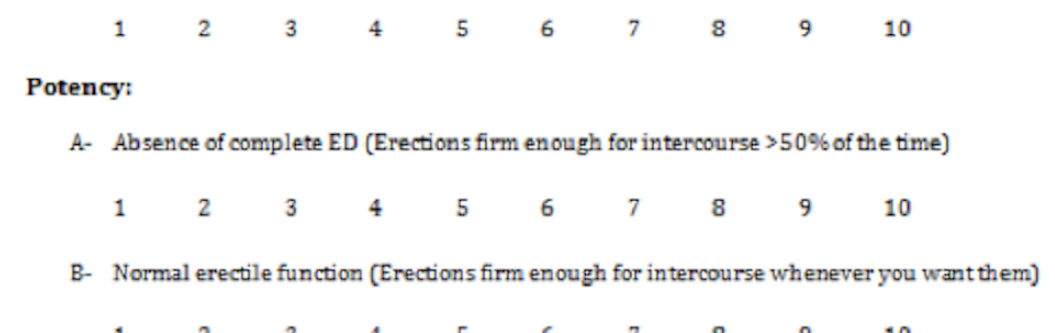

\section{No blood transfusion:}

$\begin{array}{llllllllll}1 & 2 & 3 & 4 & 5 & 6 & 7 & 8 & 9 & 10\end{array}$

Cost:

$\begin{array}{llllllllll}1 & 2 & 3 & 4 & 5 & 6 & 7 & 8 & 9 & 10\end{array}$

No urethral catheter:

$\begin{array}{llllllllll}1 & 2 & 3 & 4 & 5 & 6 & 7 & 8 & 9 & 10\end{array}$

Figure S1 Pre-operative assessment of personalized treatment priorities. 